\title{
Faecal tests in the early detection of colorectal cancer
}

\author{
Joanna Kowalik \\ Diagnostic Laboratory of The Bonifratri Order Hospital of Saint John Grande, Krakow, Poland
}

Gastroenterology Rev 2020; 15 (3): 200-206

DOI: https://doi.org/10.5114/pg.2020.98541

Key words: colorectal cancer, denoamas, screening, faecal occult blood test, Cologuard, M2-type pyruvate kinase.

Address for correspondence: Joanna Kowalik, Diagnostic Laboratory of The Bonifratri Order Hospital of Saint John Grande,

54/28 tużycka St, 30-658 Krakow, Poland, phone: +48 606610 730, e-mail: asia.kowalik77@gmail.com

\begin{abstract}
Colorectal cancer is one of the most common cancers in the world. It is the second most common cause of cancer deaths in both genders in Poland. Screening tests allow for early cancer detection, resulting in reduced mortality and better prognosis. Tests include a stool test for occult blood, checking for biomarkers in faeces, and stool DNA testing. Colonoscopy remains the gold standard in the diagnosis of cancer, both in Poland and around the world. To convince patients of the importance of such testing, it is necessary to have a wider knowledge of all the available diagnostic tests, to understand their advantages and disadvantages. This article will give descriptions of the respective tests and compare their effectiveness in the diagnosis of colorectal cancer.
\end{abstract}

\section{Introduction}

Colorectal cancer is the third most common malignancy in men and women. The number of cases in Poland (of both colon and rectum) in 2016 was 18,571, which shows the scale of the problem. Colorectal cancer is a disease with considerable dynamics of increase, and it is the second most frequent cause of death [1]. Since 1990, there has been an almost two-fold increase in the number of colon cancer cases in both women and men. The number of deaths from malignant colorectal tumours in men increased almost two-fold in 19802016 , and by $30 \%$ in women. Given the overall increase in the number of people aged over 65 years and the current incidence trends, it has been forecast that in 2025 the number of cases of colorectal cancer in Poland will be around 24,600, including 15,500 men and 9,900 women. Five-year survival in patients does not exceed $50 \%$ [2]. The best way to improve the course of the disease and the effectiveness of treatment is screening (prophylactic), which is used to detect the cancer at an early stage of advancement, thus increasing the possibility of effective treatment. In the US, screening has significantly reduced mortality rates due to cancer since 1990 - down to just 25-30\% [3].

The screening test with the best diagnostic characteristics is colonoscopy, which is widely available and frequently performed. Nevertheless, the most common screening test for colorectal cancer is to examine the presence of occult blood in the stool, repeated every year, followed by a colonoscopy in all persons with a positive result, and a colonoscopy every 10 years for people with negative results. In Europe, some countries, including Poland, run a common program for the early detection of colorectal cancer using only colonoscopy [2].

In this era of developing diagnostics, new biomarkers are being researched, to support the diagnosis of colorectal cancer in its early stages. Studies can be found that describe the usage of tumour pyruvate kinase (Tumour M2PK) and the contribution of altered bacterial flora of the intestine to the development of cancer [4]. These potential biomarkers, although not yet used in prevention programs, constitute a major challenge to the organisations running screening programs. In 2008, the USMTF (US Multi-Society Task Force), USPSTF (US Preventive Services Task Force), and ACG (American College of Gastroenterology) modified the recommendations for screening. In addition to recommending the use of higher-sensitivity occult blood detection methods in faeces, a new method for testing DNA isolated from stool cells was also considered. At this stage, however, there are insufficient data to confirm their effectiveness. High costs also make it difficult to use them as screening tests. For this reason, colonoscopy and/or an immunochemical test for the presence of faecal occult blood are still the first-choice test methods [3]. 
This paper presents the laboratory tests available for, and capable of, the early diagnosis of colorectal cancer. The availability, practical use, and cost of the tests were taken into account. Based on the abovementioned factors, the faecal tests can be further divided into the following groups. The faecal occult tests are the most popular and widely used. The second group includes modern and multitarget stool DNA or M2PK tumour tests, which are expensive and not readily obtainable. The third group represents the future of microbiome studies, in which the diagnostics are not yet available. However, it is expected that new possibilities in CRC screening strategies will emerge.

\section{The most widely used stool tests}

\section{Faecal occult blood (FOBT) - guaiac tests}

The GFOBT (guaiac faecal occult blood test) is a lowcost examination that can be conducted on an out-patient basis. The guaiac test detects the peroxidase activity of haemoglobin. In contact with the heme, and in the presence of hydrogen peroxide, the guaiacol soaked in the reaction strip oxidises to a blue-coloured derivative. This is a qualitative test [5]. An example of a guaiac test is the Hemoccult test. A significant limitation of this test is its low analytical specificity - all compounds with peroxidase properties give a positive result. Positive test results can be returned for peroxidases from, for example, meat, fruit, and vegetables. Positive results can also occur in patients taking nonsteroidal anti-inflammatory drugs, whose action can cause gastrointestinal bleeding un-related to the neoplastic process. On the other hand, false negatives can be caused by vitamin $C$ in high doses. To properly perform a guaiac test, it is necessary to take stool samples three times, which is troublesome for patients. It is also important to follow a special diet. Three days before the test, one should avoid eating pork, beef, rabbit meat, and vegetables, such as broccoli, cauliflower, and parsnips. Non-steroidal anti-inflammatory drugs and vitamin C should be discontinued 7 days before the planned examination [3]. Another limitation of this method is the inability to differentiate between bleeding from the upper and lower gastrointestinal tracts, as well as the fact that the test does not detect haemoglobin in a concentration below $600 \mu \mathrm{g} / \mathrm{g}$ of faeces. For this reason, polyps, which are precursors of colorectal cancer and bleed less, cannot be detected [5].

The Hemoccult Sensa test is a modified version of this test. It has an increased diagnostic sensitivity of $92 \%$ for colon cancer, compared to $86 \%$ for the standard Hemoccult test. The specificity of both tests is similar. The improvement sensitivity of the Hemoccult Sensa test is thanks to the use of a so-called triple slide, designed to allow patients to collect serial samples over 3 days. This increases the probability of detecting occult blood. Additionally, a higher level of stability and colour reaction intensity increases the readability, resulting in easier interpretation of the test results. Despite the limitations, it has been confirmed that running a Hemoccult or Hemoccult Sensa test every 1 to 2 years is an effective screening method for colorectal cancer. Large, randomised clinical trials have shown that guaiac screening tests reduce the number of deaths from colorectal cancer by $16 \%$ [3]. In a large study in Minnesota in the United States, a $27 \%$ decrease in mortality was confirmed [5].

\section{Examination of the presence of faecal occult blood - immunochemical methods}

The iFOBT (immunochemical Faecal Occult Blood Test) utilises antibodies directed against human haemoglobin, which in fact quantify their content in faeces [3]. The haemoglobin present in the stool sample reacts with a specific monoclonal antibody (Figure 1). The hae-

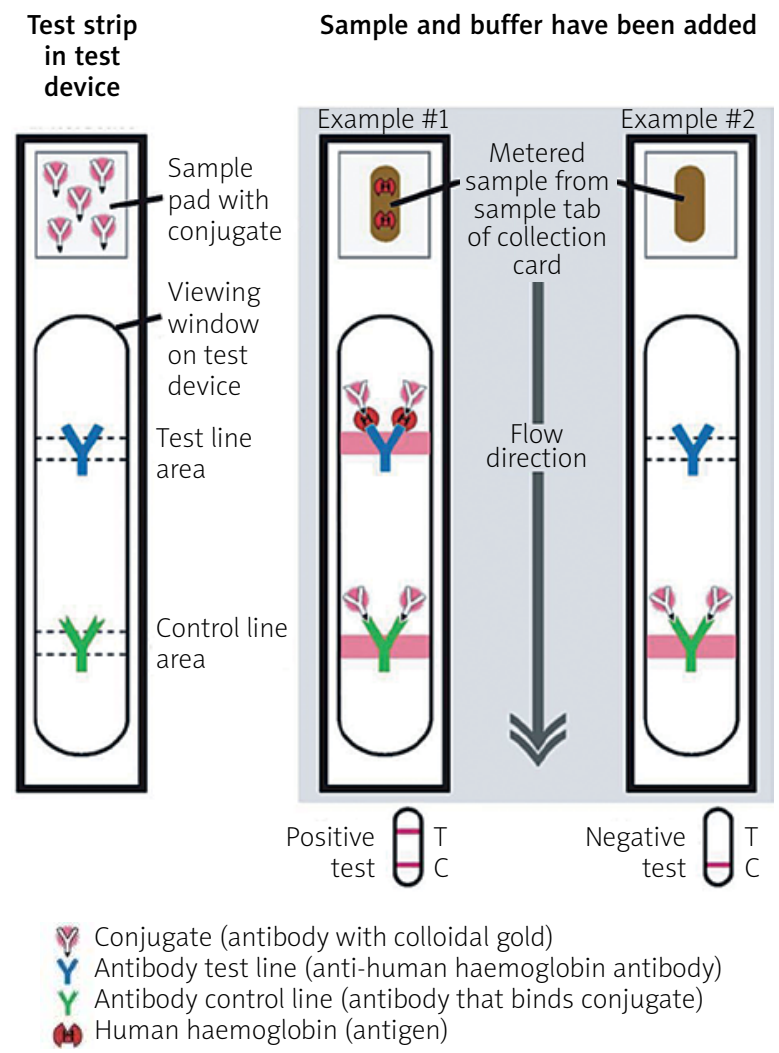

Figure 1. Diagram of the course of the latent detection of blood in the stool using the immunochemical method. Gut and Liver 2014; 8: 11730. https://doi.org/10.5009/gnl.2014.8.2.117 [21] 
moglobin/ antibody has a colloidal gold complex and is seized upon by the membrane antibodies to produce a visible line on the test strip (line T). Gold-marked antibodies (not bound with haemoglobin) are found in the $\mathrm{C}$ control line. The presence of the control line indicates that the test has been carried out correctly.

The advantage of this method is the ability to automate and analyse the results. Also, the probability of a valid test evaluation is greater because it does not require dietary restrictions (antibodies do not cross-react with the haemoglobin of other species). It is also easier to obtain material for testing, because only one or two stool samples are needed. Because the haemoglobin protein portion is digested in the upper gastrointestinal tract, as a diagnostic method these tests are limited to the detection of bleeding from the colon and rectum. A special advantage of this method compared to guaiac methods is the ability to determine haemoglobin with a much lower concentration (as low as $25 \mathrm{ng} / \mathrm{ml}$ of the assay buffer) [3]. The disadvantage of this method is the higher cost of the test. Additionally, tests differ by manufacturer. For example, in the way the results are presented. Therefore, it is impossible to compare them on a one-to-one basis. In general, the concentration of haemoglobin in nanograms per millilitre of test buffer is assumed [5]. Attempts at standardisation and proposals for expressing the haemoglobin content in micrograms per gram of faeces are still being made [3]. Comparing the occult blood detection tests in the diagnosis of colorectal cancer, many studies have shown that immunochemical tests are characterised by greater sensitivity, especially in the detection of cancer and high-grade dysplasia when compared to the Hemoccult tests [3].

In a study of 2351 healthy subjects and 161 reported gastrointestinal complaints of Australians, immunochemical tests proved to be the more sensitive method of detecting colorectal cancer than Hemoccult Sensa ( $87.5 \%$ vs. $54.2 \%)$, while both tests were characterised by similar specificity (96.6\% vs. $97.5 \%)[6,7]$. In another screening study involving 10,673 French people, twice as many cases of cancer and advanced adenomas were detected with an immunochemical assay (haemoglobin detection limit of $50 \mathrm{ng} / \mathrm{ml}$ of assay buffer) compared to the guaiac test, without differences in specificity. In the French population, the effect of changing the limit of haemoglobin detection on the diagnostic sensitivity of the tests was also assessed. With the change in the detection limit of haemoglobin from $\geq 20 \mathrm{mg} / \mathrm{ml}$ to $\geq 50 \mathrm{mg} / \mathrm{ml}$ and $\geq 75 \mathrm{ng} / \mathrm{ml}$, the sensitivity of the test in diagnosing bowel cancer decreased (85\%, $67.8 \%$, and $61 \%$, respectively). However, the specificity (94-98\%) did not change [3].
In another American study, the Health Maintenance Organisations (insurance companies and healthcare providers) examined 5841 members in a group at moderate risk of colorectal cancer. A colonoscopy was performed if it returned a positive faecal occult blood test, and a fibre sigmoidoscopy in the case of a negative result. After 2 years of observation, it was found that the immunochemical tests were characterised by greater sensitivity in detecting left colon cancer $(81.8 \%$ vs. $64.3 \%$ ), but lower sensitivity in detecting large $(\geq 1 \mathrm{~cm})$ advanced adenomas in this location $(29.5 \%$ vs. $41.3 \%$ ). In both cases, the immunochemical test was characterised by a higher specificity compared to the Hemoccult Sensa (96.9\% vs. $90.1 \%$ for colorectal cancer and $97.3 \%$ vs. $90.1 \%$ for adenomas) [8]. A subsequent study of a Dutch group of 20,623 individuals, randomly divided into subgroups, was performed using immunochemical testing of one faecal sample and Hemoccult testing of three faecal samples. 10,993 individuals returned the test, 4836 (46.9\%) in the GFOBT group and 6157 (59.6\%) in the IFOBT group. More than twice as many advanced adenomas and twice as many colon cancers were detected using the immunochemical tests, compared with the Hemoccult. However, the immunochemical test had a slightly lower specificity (97.8\% vs. 99.0\%) [9]. In May 2016, a meta-analysis was published. It compared the effectiveness of two faecal occult blood detection tests in the diagnosis of colorectal cancer. The authors analysed databases for the period February 2013 to June 2014, and they compared five large studies assessing these tests in the final phase of the study. Over 50,000 patients aged 50-75 years participated in all five of the studies. It was found that immunochemical methods give more positive results compared to guaiac methods. In a study of a group of 2500 patients, a positive result was obtained in $9.5 \%$ of the subjects with the immunochemical test, and 3.9\% in the guaiac test. The immunological method also detected more pathological changes that were confirmed later in the colonoscopy: $9.3 \%$ vs. $1.4 \%$. In addition, the immunochemical methods were better accepted by those participating in the study [10].

\section{New and rarely used tests based on biomarkers. \\ Determination of the pyruvate kinase tumour}

The pyruvate kinase tumour (Tumour M2 PK) is a dimeric form of the glycosylation enzyme of type $M 2$ pyruvate kinase. The enzyme is the catalyst of the last reaction stage of the glycolytic sequence, it converts phosphoenolpyruvate into pyruvate, and it is responsible for the production of ATP within the metabolic 
pathway in which it participates [11]. All multiplication cells are secreted by the $M 2$ isoenzyme. Enzymatic studies of many types of tumours have shown that tumour growth is associated with an increase in total pyruvate kinase activity. There is a shift towards expression of the M2-type isoenzyme instead of the tissue-specific forms of this enzyme, such as L-PK, which is characteristic of the liver and kidneys; M1-PK, which is characteristic of the muscles and brain; and R-PK, which is characteristic of erythrocytes. Increased expression of M2-PK remains under the control of the gene system of ras and transcription factors SP-1 (specificity protein 1) and HIF-1 (hypoxia-inducible factor 1), which are significantly altered in tumours of the gastrointestinal tract [12]. M2-PK can exist in a tetrametric form with high affinity, and in a dimeric form with low affinity to phosphoenolpyruvate (PEP). The tetrametry-dimer ratio M2-PK determines the proportional share of carbon atoms derived from glucose, used in the energy chain of glycolysis (tetrametric form), or directed to synthesis processes (dimer form). In cancer cells, M2-PK mainly takes a dimeric form. This is due to the occurrence of direct interactions with various oncoproteins, such as pp60V-src kinase and HPV-16 E7. In patients with adenoma and colon cancer M2-PK, the tumour is released both into the blood and into the faeces. Commercially available tests are based on the ELISA method, using two monoclonal antibodies that bind to the dimeric form of M2-PK and do not cross-react with other forms of the enzyme. An antigen-antibody complex is formed with the M2-PK isozyme present in the test sample. After rinsing, an antibody is added to detect the resulting complex and antibodies bound to the enzyme. After the addition of the substrate, the enzyme catalyses the reaction, the product of which is quantified by spectrophotometry to measure the intensity of the colour. The intensity is proportional to the product concentration, i.e. to the amount of antigen in the test sample. The level of M2-PK in plasma increases in both gastrointestinal tumours and lung, kidney, breast, and cervical carcinomas. This test is useful in monitoring the course of these cancers. German authors published the results of a study including 303 patients undergoing colonoscopy and M2-PK staining in the faeces. They examined 173 patients in the control group without diagnosed pathological changes in the colonoscopy, and 130 patients with CRC. For the cut-off level of M2PK $4 \mathrm{U} / \mathrm{ml}$, a sensitivity of $83 \%$ for colon cancer and $73 \%$ for rectal cancer, with a specificity of $82 \%$ was found. The tumour M2-PK levels also correlated in the stools of CRC patients with the tumour grade, according to TNM and Dukes classification. There was a significant difference ( $p=0.007$ ) between the control group and the T2 tumour stage, and a highly significant difference ( $p<0.001$ ) between the control group and the T3 and T4 stages. Dukes classification also revealed a significant difference $(p<0.0087)$ between the control group and stage $A$ according to this scale, and a highly significant difference $(p<0.001)$ between the control group and stages B to D. The authors suggest using the M2PK of the tumour in combination with endoscopy for positive results, as a practical approach to reducing the number of deaths from colon and rectal cancer [11].

In 2009, a paper was published presenting the determination of M2-PK in 4854 volunteers aged between 19 and 94 years. Men accounted for $50.7 \%$, and women $49.3 \%$. The subjects received faecal containers, were instructed how to retrieve the material, and were to provide the sample within $48 \mathrm{~h}$ at room temperature. The M2-PK assay was performed using the ELISA for the M2-PK dimer form. The result was considered positive after exceeding $4 \mathrm{kU} / \mathrm{l}$. In 4425 persons ( $91 \%$ of respondents), a result of $<4 \mathrm{kU} / \mathrm{l}$ was obtained, which corresponded with normal values. Concentrations above $4 \mathrm{kU} / \mathrm{l}$ were obtained in 429 subjects (9\% of respondents), in whom 177 (4\% in this group) levels above $6 \mathrm{kU} / \mathrm{l}$ were found. The dependence of the percentage of patients with a positive M2PK test as a function of age was also demonstrated. For the 50-59-year age group, the percentage of patients with a positive result was $9.2 \%, 12 \%$ in the 60-69-year age group, and 16\% in the 70-79-year age group. The diagnostic specificity was at a level of 71-98\%. The obtained results showed the usefulness of M2-PK in faeces as a fast, easy, non-invasive, and economically advantageous method of screening for colorectal cancer [12].

In 2016, Italian researchers published a study in which they compared the M2-PK kinase assay and the iFOBT test in a population with no symptoms of colorectal cancer. In total 1027 asymptomatic subjects were examined, aged $59-74$ years, of whom $49.1 \%$ were women. Two faecal samples for FIT and M2-PK were evaluated. Subjects with at least one positive faecal test were invited to undergo a colonoscopy. Overall, 572 of 1027 subjects underwent both FIT and M2pk evaluations. Total positive results increased from $12.3 \%$ to $16.3 \%$, with the addition of the M2PK test to FIT. In particular, faecal M2PK assessment permitted the detection of 18 FIT-negative subjects with neoplasm revealed by colonoscopy. The M2-PK study alone had lower sensitivity compared to iFOBT. The authors concluded that an M2-PK tumour assay is not a reliable alternative to FIT for CRC, but in combination with FIT it offers the potential to detect additional adenomas and cancers that do not bleed, or only bleed intermittently, without 
reducing the participation rate and without increasing the endoscopy workload $[13,14]$.

\section{DNA testing of cells isolated from stools}

The US Multi-Society Task Force (USMTF) and the American College of Gastroenterology (ACG) were the first to consider DNA testing of cells isolated from stools in their guidelines for colorectal cancer screening. Cologuard is the only stool-DNA screening test for detecting colon cancer that is approved by the Food and Drug Administration (FDA). First-generation genetic tests focused on the search for 21 specific mutations for this cancer within APC genes, K-ras, P53, microsatellite instability (MSI) assessment of BAT-26, and determination of the degree of DNA damage based on the length of DNA fragments [3]. The results of colonoscopy screening carried out as part of two multi-centre studies, in which first-generation genetic tests and guaiac faecal occult blood tests were compared, showed that the study of DNA isolated from faecal cells is characterised by low sensitivity in the diagnosis of colorectal cancer. There have been many works that showed large differences in the sensitivity of the tests. In the comparative analysis of the genetic test, where 21 mutations and Hemoccult were evaluated in a subgroup of 2507 people, the sensitivity of DNA testing was estimated at $52 \%$ and the guaiac test at $13 \%$. In another study, Ahlquist et al. used a similar panel and achieved $90 \%$ sensitivity level for the DNA test. This level was a result of the differences in the selection of the population for research. Higher sensitivity was observed by examining patients with an already diagnosed cancer, often at an advanced stage. The authors emphasise that the research methodology could have influenced the obtained results as well [15].

Increasing the sensitivity of DNA tests has been made possible thanks to the development of second-generation tests. The most important modifications were the introduction of a buffer that increases the stability of DNA, changes to the DNA binding method, and introduction of a metering marker for the vimentin gene promoter. Studies of this second-generation DNA testing in small groups of patients have shown higher sensitivity than first-generation tests [5]. For example, another large, multi-centre study was conducted in the US among 3764 people. Second-generation DNA tests revealed three times more adenomas $(>1 \mathrm{~cm})$ when compared to the first-generation tests, four times more than Hemoccult tests, and three times more than the Hemoccult Sensa test [16]. Another multi-centre study of 9989 patients showed that the DNA test had a sensitivity of $92 \%$ for colorectal cancer, while the iFOBT test had a sensitivity of $73 \%$, with both tests characterised by a similar specificity of $95 \%$ [17]. Developments in the field of molecular biology have also led to the development of a new generation of genetic testing. This combines four methylation markers: BMP3 (bone morphogenetic protein 3), NDRG 4 (gene silenced by N-myc, encodes a protein belonging to the $\alpha / \beta$-hydrolase superfamily), vimentin, and TFPI2 (tissue pathway inhibitor 2), as well as seven reference mutations in KRAS, $\beta$-actin, and determination of haemoglobin. In addition, the use of PCR in real time provides 100-1000 times greater analytical sensitivity than the first-generation tests. In 2016, several major studies were presented to prove that DNA tests, especially of the third generation, have high sensitivity (higher when compared to the iFOBT test) and are recommended for three-yearly screening for colorectal cancer [18]. Although DNA tests from 2014 have been introduced to recommendations for screening colon cancer by various large American healthcare organisations, their use is still limited by their high cost [4]. In order for genetic tests to enter global screening programs, large studies of target populations are needed to confirm the diagnostic validity of individual types of tests or their combinations, and to reduce the cost of this method [3].

\section{Future opportunities \\ Examination of bacterial flora in faeces}

Recent research suggests the involvement of bacterial flora in the development of colorectal cancer. The enormous development of metagenomics - the study of a genetic material of microorganisms living in the human body (microbiome) - has made it possible to characterise the correct composition of the microflora, and thus identify changes in specific disease entities. The nucleotide sequencing of the V1-V3 variable regions of the bacterial 16S r RNA gene has become the standard method of identifying bacterial populations. Each species has a unique sequence of this gene. However, within the area of this gene are highly conserved regions that can be used to multiply selected regions of the $16 \mathrm{~S}$ rRNA gene using PCR, to then determine the sequence of the resulting PCR product. The obtained sequence is compared to the sequence database, which allows for identification of the microorganism. The intestinal flora exists in $90 \%$ of absolute anaerobes, represented by producers of volatile fatty acids (Bacteroides, Eubacterium) and lactic acid (Bifidobacterium and Lactobacillus). The auxiliary microflora are facultative anaerobic bacteria - E. coli, Enterococcus. A small percentage are bacteria such as Clostridium, Proteus, granules, and Pseudomonas. Intestinal symbiotic bacteria increase intestinal stability and inhibit intestinal colonisation by pathogenesis. It is also becoming clear that the intestinal dysbiosis plays a key role in the carcinogenesis 
[19]. Patients with CRC have different intestinal microbiota than healthy people. In a 2013 study conducted in three large hospitals in Washington, US, on a group of 141 patients, 47 of whom had confirmed colon cancer, and a 94-subject disease-free control group, an analysis of the 16S rRNA gene of faecal microorganisms was performed, and it was shown that patients with colorectal cancer have less differentiated intestinal microbes than the control group. In the patients with CRC, there was an increased presence of the bacteria responsible for inducing inflammation of the Bacteroides type (16.2\% vs. $9.9 \%$ ), Fusobacterium (31.9\% vs. $11.7 \%$ ), and much less bacteria from the Clostridium or Cryptococcus group (68.6\% vs. $77.8 \%$ in the control group), which protect the body against the development of tumours [19]. In the cancer process, the Streptococcus bovis group is of great importance. It can promote cell proliferation and interfere with apoptosis in tumour cells, inducing the production of pro-inflammatory cytokines. Other bacteria associated with colorectal cancer are Helicobacter pylori and genotoxic Escherichia coli, which were both present in the mucous membrane of the colon tumour and in normal tissue in patients with confirmed colon cancer [6]. In 2012, also in North America, a presentation was given to describe the participation of another bacterium in colon cancer: Fusobacterium nucleatum. This is a highly invasive Gram-negative anaerobic bacterium found in parts of the mouth and digestive tract, acting as a commensal microflora, whose presence has been linked to the existence of many diseases, from appendicitis to inflammatory bowel disease. This bacterium can contribute to the development of colon cancer by invading the colonic mucosa and inducing local inflammation and increased cytokine expression, leading to colon disease. More convincing evidence that infection with F. nucleatum directly affects colorectal cancer and is not the result of disease progression can be found in the two most recent reports showing that $F$. nucleatum, through the unique adhesion of FadA and the recruitment of immune cells infiltrating cancer, generates an oncogenic pro-inflammatory microenvironment that promotes colorectal cancer. New data published by Zackular et al. provide valuable insight into the colorectal cancer screening tests. The authors demonstrated that advanced analyses of human faecal microbiome, which arises in the advent of adenoma toward carcinoma of the colon, can improve these colorectal cancer screening strategies. This study was conducted on patients in four major oncology centres in Canada and the United States. The research team clearly distinguished the faecal microbiome composition of healthy, adenoma, and carcinoma groups. The study demonstrates that the combination of data on the body mass index, a known clinical risk factor of colorectal cancer, gFOBT, and the microbiome data can provide excellent discriminatory ability between healthy individuals and those with colonic lesion [6]. The impact of this bacterium on the development of colorectal cancer has also been demonstrated in a recent European study in which F. nucleatum was identified as a new risk factor for the progression of adenoma to cancer, which could have an impact on survival in these patients [20]. Studying the human microbiome in relation to age, race/ethnicity, and different stages of tumour can help to create a fast and reliable colorectal cancer test for use in nationwide colorectal cancer screening programs based on the human faecal microbiome. Research in this area is constantly evolving.

\section{Summary}

Every year, around one million cases of colon cancer are diagnosed around the world, leading to 529,000 deaths [12]. Due to the slow development of this disease, screening is of particular importance because it can significantly reduce mortality. Despite widespread prevention programs, there is still low reporting for this examination. Colonoscopy, being recognised as the gold standard for such, does not enjoy much trust among patients, although statistics show that complications occur very rarely - once per 1000 tests. Nevertheless, patients prefer non-invasive tests. To this end, there have been a wide range of tests described. The first non-invasive tests, faecal occult blood determinations, were introduced as far back as the 1970s. Each test has advantages and disadvantages, and unfortunately none of them can replace colonoscopy in terms of diagnostic characteristics. Although in some countries, especially those in which the level of healthcare is high and adequately funded, iFOBT tests and DNA stool detection tests have been introduced for recommended colorectal cancer screening, but these are still not common options. There is still a lack of large, randomised trials that could confirm the efficacy of new biomarkers in the screening process.

The Multi-Society Task Force released a set of recommendations in 2017 that included the currently available test methods, as well as the latest versions. Colonoscopy performed every 10 years was recommended as the basic, first-line method for screening, with iFOBT repeated every year. In European countries, screening programs are also based on colonoscopy (Poland, Germany, Austria, Italy) and iFOBT (the Netherlands). In some countries (France, Finland, United Kingdom) gFOBT or sigmoidoscopy (UK) are used. The authors of the MSTF recommendations emphasise that in the case of colorectal cancer, the optimal screening 
method has yet to be determined. In accordance with the European guidelines, new methods of screening may be introduced to the healthcare system only if their effectiveness is confirmed in randomised trials. On this basis, the approved methods in screening tests are iFOBT, gFOBT, and Cologuard. Other methods do not have sufficient evidence of effective reduction of mortality from colorectal cancer. Studies are underway to confirm the effectiveness of screening tests, e.g. microbiome testing. It seems to be the right direction for future research [21]

\section{Conflict of interest}

The authors declare no conflict of interest.

\section{References}

1. Wojciechowska U, Czaderny K, Ciuba A, et al. Nowotwory złośliwe w Polsce w 2016 r. Krajowy Rejestr Nowotworów.

2. Kubiak A, Kycler W, Trojanowski M. Epidemiologia i profilaktyka raka jelita grubego w Polsce. Probl Hig Epidemiol 2014; 95: 636-42.

3. Vu HT, Burke CA. Postęp w badaniach przesiewowych w kierunku raka jelita grubego. Medycyna po dyplomie 2010; 19.

4. El Zoghbi M, Cummings LC. New era of colorectal cancer screening. World J Gastrointest Endosc 2016; 8: 252-8.

5. Schreuders BH, Grobbee EJ, Spaander MCW, Kuipers EJ. Advances in FECAL tests for colorectal cancer screening. Curr Treat Options Gastroenterol 2016; 14: 152-62.

6. Narayanan V, Peppelenbosch MP, Konstantinov SR. Human fecal microbiome-based biomarkers for colorectal cancer. Cancer Prev Res 2014; 7: 1108-11.

7. Smith A, Young GP, Cole SR, et al. Comparison of a brush sampling fecal immunochemical test for hemoglobin with sensitive guaiac-based fecal occult blood test in detection of colorectal neoplasia. Cancer 2006; 107: 2152-9.

8. Alison JE, Sakoda LC, Levin TR, et al. Screening for colorectal neoplasms with new faecal occult blood test: update on performance characteristics. J Natl Cancer Inst 2007; 99: 1462-70.

9. Van Rossum LG, van Rijn AF, Laheij RJ, et al. Random comparison of guaiac and immunochemical fecal occult blood test for colorectal cancer in screening population. Gastroenterology 2008; 135: 82-90.

10. Mousavinezhad M, Majdzadeh R, Sari AA, et al. The effectiveness of FOBT vs. FIT: a meta-analysis on colorectal cancer screening test. Med J Islam Repub Iran 2016; 30: 366.

11. Hard PD, Schlierbach P, Toepler M, et al. Poziomy kinazy pirogronianowej guza (Tumor M2-PK) w kale: czułość, swoistość i korelacja ze stopniem zaawansowania rozwoju guza w raku jelita grubego. Konferencja NCRI na temat raka, 2-5 października 2005 roku, Birmingham, United Kingdom.

12. Tonus K, Neupert G, Witzel K. Badania przesiewowe na obecność kinazy pirogronianowej M2 w stolcu u chorych z inwazyjnym i przedinwazyjnym rakiem jelita grubego: szacunkowa swoistość metody oraz wyniki uzyskane w grupie 4854 ochotników przedstawione w funkcji wieku. Nowotwory J Oncol 2009; 59: 75-81.
13. Caviglia GP, Cabianca L, Fagoonee S, Gili FM. Colorectal cancer detection in an asymptomatic population: fecal immunochemical test for hemoglobin vs. M2-type pyruyvate kinase. Biochem Med 2016; 26: 114-20.

14. Imperiale TF, Ranschoff DF, Itzkowitz SH, et al. Fecal DNA versus fecal occult blood for colorectal- cancer screening in an average-risk population. $\mathrm{N}$ Engl J Med 2004; 351: 2704-14.

15. Ahlqiust DA, Sargent DJ, Loprinzi CL, et al. Stool DNA and occult blood testing for screen detection of colorectal neoplasia. Ann Intern Med 2008; 149: 441-50.

16. Imperiale TF, Ransohoff DF, Itzkowitz SH, et al. Multitarget stool DNA testing for colorectal cancer screening. N Engl J Med 2014; 370: 1287-97.

17. Berger BM, Levin B, Hilsden RJ. Multitarget stool DNA for colorectal cancer screening: A review and commentary on the United States Preventive Services Draft Guidelines. World J Gastroenteroint Oncol 2016; 8: 450-8.

18. Ahn J, Sinha R, Pei Z, et al. Human gut microbiome and risk for colorectal cancer. J Natl Cancer Inst 2013; 105: 1907-11.

19. Flanagan L, Schmid J, Ebert M, et al. Fusobacterium nucleatum associates with stages of colorectal neoplasia development, colorectal cancer and disease outcome. Eur J Clin Microbiol 2004; 33: 1381-90.

20. Chaber A, Chaber-Ciopińska A. Badania przesiewowe w kierunku raka jelita grubego - najnowsze zalecenia MSTF 2017. Medycyna po Dyplomie 2018; 6.

21. Allison JE, Fraser CG, Halloran SP, Young GP. Population screening for colorectal cancer means getting FIT: the past, present, and future of colorectal cancer screening using the fecal immunochemical test for hemoglobin (FIT). Gut Liver 2014; 8: 117-30.

Received: 14.07.2019

Accepted: 8.09.2019 